Concept Mapping: Renewing Learning and Thinking

Proc. of the Eighth Int. Conference on Concept Mapping

Medellín, Colombia 2018

\title{
ORGANISERS, CONCEPT MAPS, AND TEXT SUMMARISATION IN THE CLIL CLASSROOM
}

\author{
José Luis Gómez Ramos, Juan Lirio Castro, Isabel María Gómez Barreto \\ Department of Pedagogy, Universidad de Castilla-La Mancha, Spain \\ E-Mail: joseluis.gomez@uclm.es; juan.lirio@uclm.es; isabelmaria.gomez@uclm.es
}

\begin{abstract}
Because of the implementation of bilingual programmes in Spanish primary schools, both instructors and learners need to select a methodology for efficiently transferring and summarising the managed curricular content during the teaching and learning process. Concept mapping is an ideal methodology to use in a bilingual classroom; however, primary bilingual students may experience difficulties in hierarchically organising the managed curricular content. Such lack of organisation of information causes students to create less accurate concept maps and, consequently, less accurate summaries from the content. To solve this problem in organisation, we suggest the step-by-step use of some graphic organisers, which complement concept mapping. The suggested method for the transposition process from texts to paragraphs involves handling texts, creating concept maps and transposing concept maps into paragraphs. The results are well structured and summarised paragraphs facilitating cognition. In education, this pedagogical method is usefulness to students as they try to efficiently manage the curricular information, acquire meaningful knowledge, learn self-regulation and confidently answer summative exams.
\end{abstract}

Keywords: Concept mapping, visual organisers, self-regulation, bilingual primary education.

\section{Introduction}

From its experience with bilingual programmes and as a way to foster foreign languages non-linguistic disciplines (DNL), the Spanish Regional Ministry of Education in Castilla-La Mancha considers the specialisation and training of DNL instructors in the didactical and instructional methodology to be used in such programmes to be a priority (Decree 47/2017). Despite teachers' specialisation and training, one of the problems that primary students still face in the bilingual English-Spanish classroom is the lack of a method that allows them to handle, process, and meaningfully learn the curricular information in their textbooks (Gómez, Arias, \& Lirio, 2016). In this regard, the main goals in most bilingual programmes are to form a well-designed instruction and to create a protocol for observing the results of the bilingual instruction held in such programmes (Hernández \& Torres, 2010). Regarding integrated instruction, in a previous research set in a bilingual school, we observed that most of the Spanish primary students did not know how the information within their foreign language (L2) textbooks was organised. We also found that most of these bilingual learners encountered problems identifying the lexical categories of words within their books and other foreign language texts (Gómez et al., 2016) and that the three Sections and the nine Topics found in the students' textbooks were interpreted by the students as isolated chunks of information rather than an entity.

To improve students' communicative competences in the L2, the Regional Ministry of Education promotes the integration of the schools from this autonomous community to the coveted bilingual and plurilingual status. Such language promotion requires not only the instruction through an integrated curriculum but also a specific training plan for the teachers. Efficient instructional design for the content and language integrated learning (CLIL) curriculum implies the awareness of a specific pedagogical methodology (Decree 47/2017, Arts. 3, 25, 37, 38, 39). For Bruner (1999), content can efficiently be taught to any student at any age, and the main factor to be considered by the instructor is how the child perceives things. The author also states that children cannot discern by themselves the new techniques for self-learning and self-regulation. Thus, if DNL instructors are ineffective in transmitting pedagogical principles, learners will tend to learn by rote and by trial and error. To eliminate this way of learning the explicit bilingual curriculum, the Regional Ministry of Education believes that training teachers in specific pedagogical methods must become a priority. Referenced pedagogical concern does not represent a contemporary topic in the infant and primary education in Castilla-La Mancha. Manzanares and Galván-Bovaira (2012) have published a study about the importance of the in-service teachers' training factor in this region.

When planning the instruction, one of the principles that DNL teachers should consider is that the learning, teaching, and assessment theories used in bilingual classrooms must be consistent with one another. Training bilingual students in meaningful learning then evaluating them and asking for literal answers will result in their getting lower marks (Ausubel, Novak, \& Hanesian, 2010; Gómez, Lirio, Gómez, \& Garrote, 2018). For example, when using concept maps to train students, applying Ausubel's theory of assimilation and meaningful learning is critical for student evaluation. In symbiosis with such learning-evaluating principles, concept maps can be used for both formative and summative aims (Mintzes, Wandersee, \& Novak, 2005). Assessments must also offer the examinees learning 
opportunities that are linked to concepts they already know (Moreira, 2012). The main issue in the bilingual classroom is not only that instructors need to be aware of the triad teaching-learning-evaluating but also that they must provide students with the appropriate tools for success in such a globalised world. For Campelo and Bertholo (2016), today's societies are facing new labour forces where citizens use new technologies and are socially connected. Taking this situation into account, is it appropriate to ask students to memorise content and offer it back up literally in a summative exam? Would it be fair to ask primary students to make concept maps using CmapTools as a summative exam instead?

Concept mapping can lead students to achieve academic success and become more creative, both of which the Regional Ministry of Education expects from bilingual primary students. Consistent with this idea, to improve the educational system, educators should use concept maps at all educational levels (Campelo et al., 2016). Regarding such use of concept maps, Novak (2010) also affirms that education can be significantly improved simply by adopting more efficient theories of learning as well as pedagogical models and tools, thus empowering students to create their meaningful knowledge. With cognition, concept mapping, bilingualism, and primary education in mind, we recommend the implementation of concept maps in bilingual schools from the earliest ages onward. Although our research revealed outstanding results, during the instruction, we found that the students were not as successful as expected in identifying, grouping, and categorising nouns (Gómez et al., 2016). Mintzes et al. (2005, p. 78) mention that 'several new teaching strategies [...] include a range of graphic organizers. Thus, we encourage the use of graphic organisers in addition to concept maps such that students can, in a step-by-step fashion, truly assimilate concept mapping as a routine, learning-process technique.

\section{Graphic Organisers as Cognitive Facilitators in the Bilingual Programmes}

Graphic organisers other than concept maps are not powerful learning tools, but they constitute '[...] a powerful way to help students see some of the ways that information can be organized and stored' (Jackson, 2011, p. 62). These organisers are simpler than concept maps because the grouping and organising rule ' [ . . ] is less complex than the sum of all the distinguishable features of all the elements in the collection' (Bruner \& Olver, 1966, p. 417). In other words, basic organisers show grouped, unlinked, or isolated ideas, whereas concept maps show concepts formed by propositions. Some basic organisers can serve as the substructure for the bilingual primary student to later create a solid concept map that allows him or her to meaningfully learn the managed curricular content. Identifying, grouping, and classifying nouns also requires knowledge, strategy, combination, relation, selection, and association (Bruner et al., 1966). Creating a new concept map that combines the multiple attributes previously selected and organised by the students will stimulate their cognitive structures as well as a more meaningful knowledge of the concepts represented in the concept map. Though Piaget's stages are still referents in education, children's cognitive developmental stages can be improved or delayed simply by providing the appropriate stimuli or deprivation (Ausubel, 1968).

When acquiring cognition in the L2, an adequate stimulus for the primary students might be to make them aware of how knowledge is built through sequentially using related tools up to the point of creating a concept map. Instructors should make bilingual students aware of the sequential relatedness and the degree of dependence of the curricular content being transferred (Gagné, Briggs, \& Wager, 1992). Learners' cognitive and grouping structures are somewhat different from the combinatorial cognitive structures in propositional operations (Piaget, 1959). Hence, every concept map is expected to be different. For this reason, the organisers used in a sequence will imply less complexity than the subsequent propositional and combinatorial framework represented in a concept map. Because of the influence of syntactical and grammatical structures in both code-switching and transference (Clyne, 2000), in the primary bilingual schools, transfer would be a problem that affects DNL teachers. When the students do not master the sequential relationship and dependence of the content, it is impossible for them to successfully progress unless the content is rotely learned; if the new content is to be learned meaningfully, clear subsumers should exist in the learners' cognitive structures (Ausubel \& Robinson, 1972).

In the DNL subjects linked to science, concept relatedness is a relevant factor for the students to later represent the subjects as networks of knowledge (Clariana \& Kozlov, 2016). However, regarding the students' previous knowledge and learning strategies, how deep should the initial anchoring idea be? To acquire meaningful learning, ' $[\ldots]$ the existence of relevant anchoring ideas is the primary prerequisite for subsequent learning and, by definition, for sequential transfer' (Ausubel et al., 1972, pp. 143-144). However, the bilingual Spanish primary students do not always have that previous knowledge regarding content and metacognition. In our study, some students recalled part of the concepts they had learned the previous year, but most of them did not. Additionally, we observed that some 
concepts from the new textbooks were unknown to the students both in their mother tongue (L1) and in the L2. In this regard, even if the learners store new ideas in relation to previous subsumers, the new concepts are dissociable from the anchoring ideas during the retention period (Ausubel, 1968). In any case, the relation of new content or tasks is crucial for both learning and transfer (Ausubel et al., 2010). According to Haskell (2011, p. 3), transfer of learning refers to the appliance of previously acquired knowledge ' [ . . . in different contexts, and to recognize and extend that learning to completely new situations.

\subsection{Skimming and Scanning L2 Texts}

For some bilingual students, simultaneously inferencing and assimilating the information in their textbooks represents a challenge unless they have the methodological skills to succeed. Reading and learning strategies, creativity, and complex thinking skills should be taught concurrently during the curricular content instruction. That is to say, 'Bilingual students must [emphasis added] be taught how to learn' (Brisk, 2006, p. 155). When the comprehension of any text is total, reading skills involve multiple factors and extensive previous knowledge (Gagne et al., 1993). For bilingual primary students, the first step to consider is the early identification of lexical categories of words from texts, especially the noun category. The identification of lexical categories in textbooks leads the bilingual learners to a better comprehension of the content (Brisk, 2006). For this reason, efficient DNL instruction should start with skimming, scanning, and identifying word categories. Particularly for some bilingual (Spanish-English) primary students, 'Learning to read effectively presents a dilemma. Words and phrases are hard to read when they have little or no meaning [and the concept is unknown even in their mother tongue], yet reading is a powerful way to learn meanings' (Novak \& Gowin, 1984, p. 43).

\subsection{Word Recognition and Understanding}

Subject matter-the explicit content that characterizes the curriculum-refers to the conventionalised meaning of a discipline made up of lexicon, regulations, concepts, models, and theories represented in a formal, logical fashion (Phye, 1997). Learners' academic performance in identifying and understanding concepts within texts implies a set of knowledge about vocabulary and methodology; however, the traditional methods for measuring concept formation are inadequate because they overlook the dynamics and evolution of concept acquisition in children (Vygotsky, 1986). For Cañas et al. (2004, p. 135), '[ . . . the need to identify relevant concepts may require effort that distracts from the task of creating meaningful propositions. In any case, we mentioned that most Spanish bilingual primary students have a '[ . . . limited awareness of the formal meaning and logic of academic disciplines' (Phye, 1997, p. 49), so concept discerning/understanding also implies the understanding of text organisation. In terms of process, it is not possible for a child to form concepts about task accomplishment without sufficient tangible experience (Ausubel, 1952). Student success in word recognition and understanding is also influenced by the varied sets of the information involved in the teaching and learning process (phonology, semantics, and the student's familiarity with the text). Furthermore, it is certain that lexical word recognition is not a trustworthy indicator of understanding in discrimination tasks in which words and non-words must be distinguished from one another (De Groot, 2011).

\subsection{Hierarchisation of the Information}

Mintzes et al. (2005) observed that some students have problems hierarchically organising information. These authors also found that an inability to think hierarchically and link ideas can lead students to misuse the information they handle. It also appears that object categorisation is influenced by bilingualism (Bassetti \& Cook, 2011). Students who lack hierarchisation skills may not have problems if, when skimming and scanning texts, they are aware of the word categories they are looking for. Are the categories singular or plural? Countable or uncountable? Or maybe abstract? To help students grasp and organise such information as well as manage these substantives, instructors could start by teaching students the concepts, perceptions, and patterns of thing-words and invisible-words. Thing-words pertain to touchable things (tree, dog, car, book), and while they are nouns as well, invisible-words are linked to abstract concepts (thought, dream, inference, confidence). Other substantives, such as mass-words, do not represent the idea of a thing that possesses specific features or boundaries (Jespersen, 1956). As a useful source, when identifying, extracting, and organising information, bilingual students should be aware of substantives as either material or immaterial. For Glasersfeld (1995), the basis of classification and categorisation remains in the construction of equivalence, where a cluster of characteristics used as templates or prototypes distinguishes a specific item from other constructs in present and future situations. That is to say, making primary students aware of the fixed and rigid (one-dimensional) basic 
commonalities of the noun categories will help them to hierarchise more flexible (two-dimensional) objects in future situations (Craig, 1986).

\subsection{From Diagramming to Concept Mapping}

Crandall et al. (2006, p. 51) note that 'the idea of using diagrams to express logical statements has a rich history in mathematics [. . .]. The modern [emphasis added] idea of Concept Mapping takes this a step further, into the "user friendly" expression of meanings'. Our main idea and goal for the use of concept maps in bilingual programmes are the same as those presented by Aguiar et al. (2016), where concept maps are used to summarise fairly large documents. In our current research, in addition to visual facilitators, we used concept mapping for the students to transpose the information from their textbooks into paragraphs to later be studied for exams. Regardless of the students' academic level, a very common use of concept maps since their inception is in science subjects (Novak, 2010); this use has even been applied to longitudinal studies (Novak, 1991) in schools. The effectiveness of these visual facilitators is that knowledge can be expressed in two dimensions: representational and organisational. Another particularity of concept maps is the way in which the substantives are linked. On a concept map, the previously mentioned concepts are linked by verbal structures that form semantic units called propositions (Cury et al., 2014).

From the earlier mentioned theoretical background, the general goal of the instructional programme is to teach bilingual primary students to summarise information through concept mapping such that they can concisely study for each summative exam. Besides, the specific objectives of the same instructional programme is to train students in noun category identification within L2 texts, as well as noun classification, propositions recognition, concept mapping, summarising, and paragraphing for the late study.

\section{Methodology}

The study that originates this proposal consisted of a didactic intervention where, by means of a didactic approach, we attempted to address concept mapping in a primary bilingual school located in Castilla-La Mancha, Spain. To achieve our goal, we implemented the use of concept maps in this school for one academic year. The instructional programme for the meaningful retention of knowledge by means or a foreign language (PIRSC-L2) was applied to fifth graders, and the concept mapping instruction was simultaneously carried out with the instruction of the curricular content (Gómez et al., 2016; 2018). Sample encompassed sixty students not randomly assigned to experimental ( $\mathrm{n}=$ $30)$ and control $(n=30)$ groups. Also, the instruction consisted of three, three-month stages carried out over the ninemonth academic year where:

- Stage 1 was a training period in which the students were taught the basics and the underlying psychological theory of concept maps

- Stage 2 was the production period during which every student individually, in pairs, and in groups created concept maps about each topic from their textbooks

- Stage 3 was the display and assessment period in which the pupils made concept maps and gave feedback to one another using an evaluation rubric elaborated by the instructor

A tacit purpose of the concept mapping instruction was to generate in these bilingual learners cognitive schemas to be recalled during future learning situations. Based on Ausubel's meaningful learning theory (1963), we believe that the learning techniques acquired by the students are meant to be meaning $f u l$, so any material being learned serves as an activator for concept mapping. Since the students' awareness and self-regulation implies metacognition (Mercer, 2000), we made the students aware of the teaching process from the earliest stages of the instruction. The instructor's first task before applying the subsequently designed instruction was to make the bilingual students in our experiment aware of the process ${ }^{1}$ in which they would be involved. As a result, with the exception of diagramming, the objectives of the experiment were successfully accomplished by the majority of these bilingual students.

\footnotetext{
${ }^{1}$ Students involved in the research were explicitly told the main goal and objectives of the instructional programme.
} 


\section{Intervention}

Notwithstanding that the primary students enrolled in the programme were not trained on visual organisers other than concept maps, during the instruction, they were given abundant examples through the diagrams shown below. The diagrams were specifically made by the instructor to exemplify and clarify some concepts. In our opinion, had we asked the students to use organisers to reinforce the concept mapping process, more students would have more efficiently accomplished the reference goal of summarising information through concept maps.

\subsection{STEP 1: Textbook Information to Be Scrutinised}

To identify the learners' previous knowledge about the topic (biodiversity protection), the first activity consisted of brainstorming and $w h$ - questions. After brainstorming and a debate, the students individually read the text to get a general idea of it. During the active reading process, the students were asked to scrutinise the text, paying attention to substantives and unknown words. The 176-word text managed by the bilingual primary students for this activity is as follows:

Endangered species are those which are in danger of extinction. Wildlife protection groups keep lists of endangered plants and animals in order to protect them. National parks and biosphere reserves are created to protect wildlife and its environment. The Iberian linx is the most endangered cat species in the world. It exists only in the wild in some areas of Southern Spain. The Iberian Imperial eagle is an endangered species living only in restricted areas of Spain. It is considered the rarest bird of prey in the world. Monfragüe National Park in Cáceres is an outstanding example of Mediterranean forest. This park is considered a bird watchers' paradise because it has both the biggest colony of black vultures and the highest concentration of imperial eagles in the world. Doñana National Park is an area of marshes and sand dunes in southern Spain. The park has a biodiversity that is unique in Europe. It is a refuge for some endangered species, such as the Iberian imperial eagle and the Iberian linx, as well as numerous migratory birds. (Bacon \& Riach, 2014, p. 85)

\subsection{STEP 2: Noun Selection, Understanding, and Organisation}

It is necessary to point out that all the activities from Stage 2 onward also encompassed the transposition of all the topics from the textbook into summarised paragraphs through concept mapping. In the following steps $1-3$, we show one of the constituent elements of the instructional programme pertaining to the transposition process (from text to paragraph). To exemplify the explanations and make them more understandable, some activities accomplished by a student are included (Figs. 2, 3, and 7). The steps shown below will be presented in the same order as instructed; however, we will mark the introduction of the organisers we believe adequate for a more efficient understanding and creation of concept maps by the students as a 'Suggested Step'.

After a session of brainstorming, enquiring, and reading, the students were divided in pairs and asked to identify nouns in the reading material and note them down. Though the students' noun discrimination was largely accurate, a tendency to remain within the instructional programme was observed. For example, adjective and noun compounds were identified as one word (i.e., Iberian Lynx and Iberian Eagle). Because of this peculiarity, during concept mapping, the students repeated the same words in their concept maps more than once (the example can be seen in the last Fig. 6). At this point, to make students aware of the lexical or grammatical word categories, we suggest the inclusion of pie charts or bar graphs.

\subsubsection{Suggested Step (pie and bar charts)}

Used as guidelines for students to be aware of the quantity, frequency, and size of the information appearing within a foreign language text (total or partial number of nouns, verbs, adjectives), bar and pie charts can help bilingual students to visually observe how many and how frequently lexical or grammatical word categories do appear in a given L2 text. For example, if nouns appear twice as much as verbs and adjectives put together, the area of such graphic representation concerning noun data would be bigger than the areas representing verbs and adjectives. To visually represent percentages, pie charts are the most common visual organisers to show data (Harris, 1996). To present percentages, bar charts are: 
A variation of the proportional area chart family. In a bar chart, the size of each bar is proportional to the value it represents. Bar charts do not have scales, grid lines, or tick marks. The value that each bar represents is shown on or adjacent to the data graphic. The major purpose of the graphical portion of a bar chart is to visually orient the viewer to the relative sizes of the various elements of a data series. With a quantitative scale on the horizontal axis, the graphic is frequently called a bar graph. (Harris, 1996. p. 27)

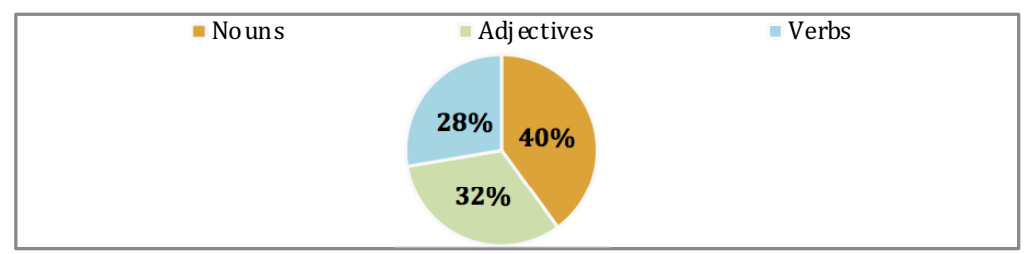

Figure 1. Hypothetical frequency of words appearing in an L2 text.

\subsubsection{Noun Understanding (tables)}

To understand, clarify, contextualise, and identify word categories and meanings, students were allowed to use English-Spanish dictionaries. Depending on the activity, the dictionaries were used individually, in pairs, or even in groups. Because most of the concepts were unknown to the students in both the L1 and L2 languages, to ensure that the concepts were understood in both languages, content from the text was acquired in English during the classroom instruction, then key words were reinforced in the Spanish language as homework (in individual and non-compulsory tasks). The glossary homework tasks consisted of listing the nouns, verbs, and adjectives, then putting them in a table organiser to be used for translation and contextualisation into the Spanish language. One weakness of the table we detected is that we did not design it to leave enough space for students to write in the Spanish propositions. The bilingual students were asked to contextualise sentences as follows:

- Translate the word into Spanish and look for the same word in the textbook

- Contextualise the word in Spanish and write the Spanish propositions using the given word

Notwithstanding that the glossary tasks were not compulsory during the course and that they were assigned for homework, almost all the students performed these tasks. In our opinion, it is crucial that key words be provided such that the bilingual primary students succeed on the exam. When learners are aware of the specialised lexicon through writing brief sentences about it, they gain a more appropriate understanding and undertake the ulterior classroom summative tasks more successfully. These pre-tasks with this lexical approach to every topic ensure the understanding of the key words as ideas and concepts for the comprehension and interpretation of subsequent concept mapping activities. Figure 2 shows a glossary example. The glossary tables and tasks where each word category was also identified as (n.) noun, (adj.) adjective, or (v.) verb were designed by the instructor.

GLOSSARY: Unit 7 "Matter and Forces"

Non-compulsory activity. Deadline April $26^{\text {th }}, 2016$.

\begin{tabular}{|c|c|}
\hline English & Write here the Spanish translation within (TRUE) propositions \\
\hline 1. Alloy (n) & Ejemplo: El latón es una MEZCLA de cobre y cinc (from page 102) \\
\hline 2. Average density (n) & a aluilidad rara flarar derunde de la Densidad Media \\
\hline 3. Biodegradable (adj) & La madera es un material Biodegradable \\
\hline 4. Bioplastic (n) & Las Bioplasticos san to talnente bucdesradables \\
\hline 5. Buoyancy (n) & Para ver la Flotalulidad en un puxina urrejames un ff \\
\hline 6. Chemical change $(\mathrm{n})$ & Les am lias Ouimiros no ruelven al es tado ertiginal \\
\hline 7. Combustion $(\mathrm{n})$ & La combustión es un cambio quínico \\
\hline 8. Contact force (n) & 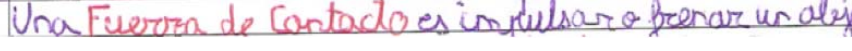 \\
\hline
\end{tabular}

Figure 2. Organiser (table) for students to accomplish the task and understand the new concepts in their mother tongue. 


\subsubsection{Euler and Venn Diagrams}

For us, one of the most successful organisers to make students aware of the concepts of hypernyms and hyponyms as well as the similarities, differences, and commonalities between things are Venn diagrams. These graphic tools describe the relationship between two or more sets of information by positioning circles that represent the information (Fig. 3). These organisers are classified as conceptual diagrams because, as in our case, they '[. . .] can be rapidly understood, tend to have a significant impact on the audience, and may be remembered longer than the same subject presented using words and numbers alone' (Harris, 1996, p. 100).

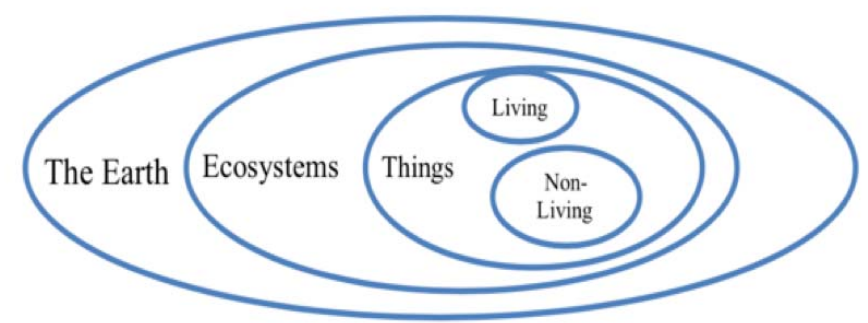

Figure 3. Information from the most general to the most specific.

\subsubsection{Suggested Steps for Noun Organisation (binary key, T-charts, tables, and Carroll diagrams)}

Despite the process of instructing students until their concept mapping was successful, we observed that the bilingual students had trouble categorising words. For noun organisation and pre-concept mapping organisation, we suggest the use of some kind of organisers. For example, for learners to conceive the dichotomy of concepts, binary keys can serve as a baseline for students to divide the information into two parts. Using a series of closed questions, these binary (yes/no) diagrams lead the students to find only two possible answers to the questions they are aware of (Fig. 4).

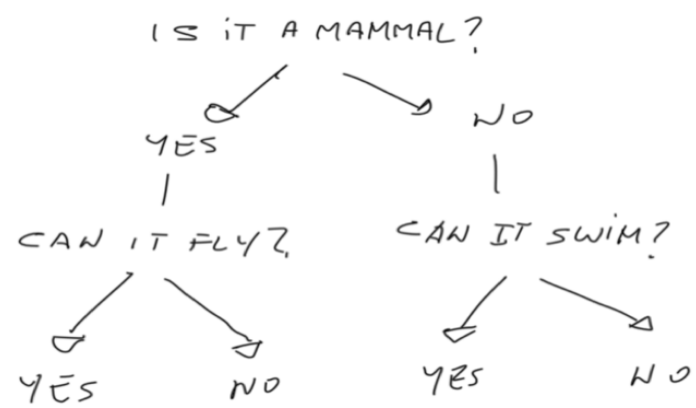

Figure 4. Through enquiring key questions, students can get yes/no answers.

More recommended organisers for bilingual students would be T-charts (anew tables) and Carroll diagrams. The justification for these organisers is that students can arrange the information in a hierarchical fashion for later use in a concept map. For example, we believe that a table with columns and rows represents words more visually than a table with columns only. Moreover, the organisation of and comparisons and relationships between words will be more rapidly stored and referenced by the students to be later transposed into a concept map. With these suggested organisers, we believe that CLIL students can organise the information more efficiently and create more accurate concept maps. These basic and easy-to-use organisers can be used to display yes/no information, show different parts of the curricular content topics, and categorise the information into hypernyms and hyponyms. Figure 5 shows the ideal uses of these organisers. 


\begin{tabular}{|l|l|}
\hline LIVING & Non-LIVING \\
\hline Tree & Car \\
Dog & stone \\
cat & Pencil
\end{tabular}

a) T- CHART

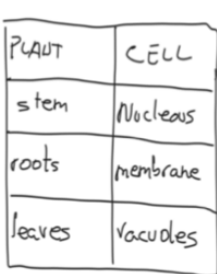

b) TABLE

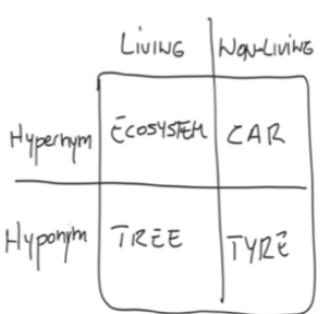

C) CARROLL DIAGRAM

Figure 5. Charts to organise and classify the information in a hierarchical fashion.

\subsection{STEP 3: Concept Mapping and Paragraphing}

In the method we applied in the bilingual school during the experiment, three types of concept maps were handled: short, average, and large. Short concept maps were made by both the instructor and the students to get a general idea about a given topic. Average concept maps were the most common and used in the classroom by both the students and the instructor to provide explanations and presentations about the topics. Finally, large concept maps were made in groups of six at the end of every didactic unit/unit of work, where the groups of students had to represent and explain to their peers the content from the unit. During the course of each didactic unit, the students made average concept maps from each topic (Fig. 6). All the students' creations were then transposed to paragraphs and subsequently used to study the topics for the exams.

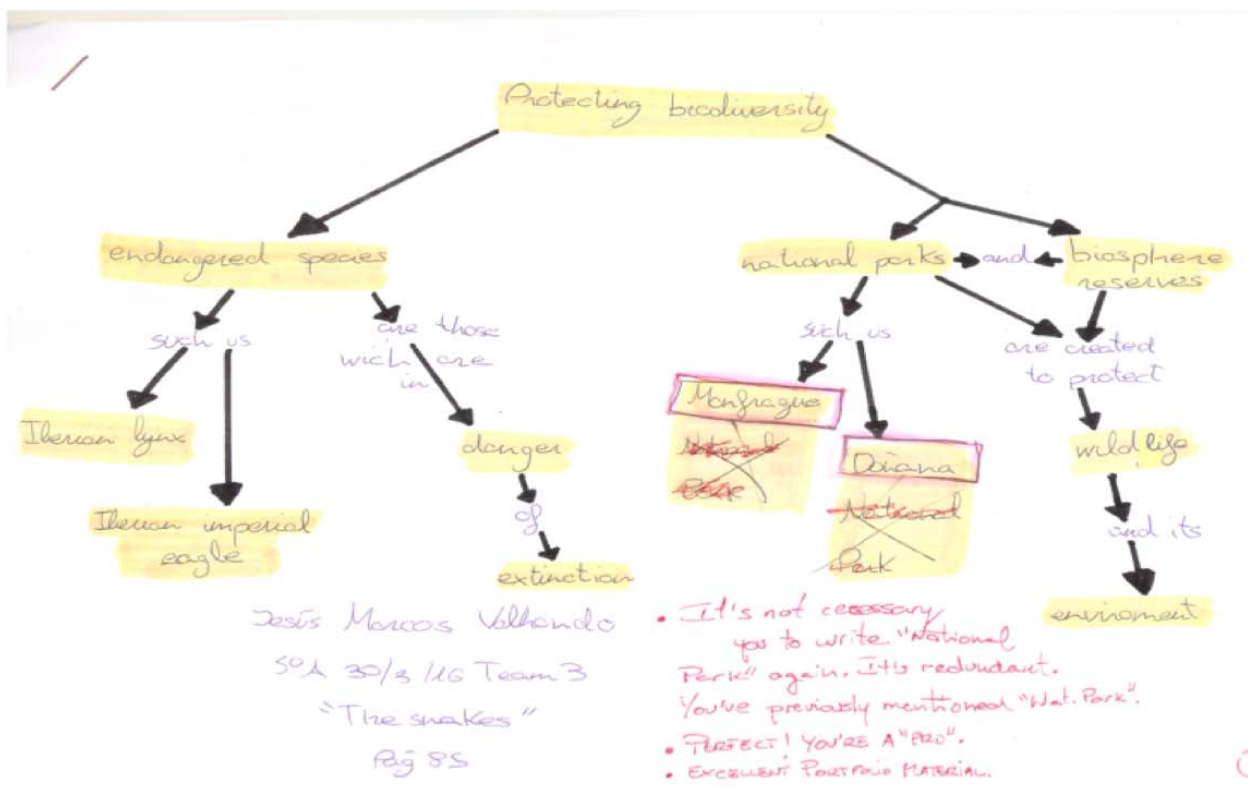

Figure 6. Concept map created by a 10-year-old from the 176-word text referenced in 2.1 .

\subsubsection{Paragraphing the Concept Map}

The concept mapping process concluded with paragraphing, where the students had to transpose the information from their concept maps into paragraphs. The aim of this activity was to help bilingual students summarise the information from their books through concept mapping. During the transposition process from the book to the original paragraph, the pupils themselves managed all the information to be learned for the exam (including concept mapping). The result of such high-order thinking skills can be observed in Figure 7, which shows that the original 176-word text referenced in 2.1 has been transposed into a 47 -word paragraph. 




Figure 7. Summary made by a 10-year-old student through concept mapping (from 176 words to 47 words).

Paragraph in Figure 7 above illustrates that biodiversity protection is the main idea, whereas the controlling ideas are the endangered species living in the biosphere reserves and the national parks. Also consequential is that the first sentence encompasses the organised ideas that will later be developed, explained, and exemplified in the subsequent sentences within the same paragraph. In our opinion, a primary student can only create such an original and professional paragraph through a concept map. Besides implying high-order thinking skills, the complexity involved in the transpositional process also implies the student's awareness of the metacognition involved in concept mapping.

\section{Conclusion}

In our attempt to introduce concept mapping to Spanish bilingual primary schools, we observed that concept maps are efficient tools for students to help them absorb the curricular information to be learned. However, in teaching concept mapping to students, hierarchising information can be a challenge for some of them (Mintzes et al., 2005). With regard to the instructional design, a limitation of our previous study was the omission of organisers that allowed learners to accurately organise information. Despite such a limitation, the students successfully achieved the main goal of transposing the information through concept mapping where, at the end of the PIRSC-L2, most students were able to scrutinise the texts, extract the relevant information from them, make a concept map with the selected information, and transpose the information from the concept map into a paragraph for the late study of the information. In this regard, Novak (2010) sees concept mapping as an efficient technique for learners to study. The consequence of such an act of metacognition empowered the students to autonomously learn the curricular information for the exams. However, to discover if student empowerment has both practical and theoretical consequences like self-regulation and cognition we will turn this proposal into a future research whose expectation is to apply the entire process and subsequently collect data sufficient for a quantitative analysis.

\section{References}

Aguiar, C., Cury, D., \& Zouaq, A. (2016). Automatic Construction of Concept Maps from Texts. In A. J. Cañas, P. Reiska, \& J. Novak (Eds.), Proceedings of the 7th International Conference on Concept Mapping (Vol. 2, pp. 20-30).

Ausubel, D. P. (1952). Ego Development and the Personality Disorders. New York, NY: Grune \& Stratton.

Ausubel, D. P. (1963). The Psychology of Meaningful Verbal Learning. New York, Grune \& Stratton.

Ausubel, D. P. \& Robinson, F. G. (1972). School Learning: An Introduction to Educational Psychology. London: Holt, Rinehart \& Winston.

Ausubel, D. P., Novak, J. D., \& Hanesian, H. (Reimpresión 2010). Psicología Educativa: Un Punto de Vista Cognoscitivo. (2 Edición). México, Trillas. 
Bacon, T. \& Riach, M. (2014). Natural Science: Primary 5. Zaragoza: Edelvives.

Bassetti, B., \& Cook, V. (2011). Relating Language and Cognition: The Second Language User. In V. Cook \& B. Bassetti (Eds.), Language and Bilingual Cognition (Chapter 7, pp. 143-190). New York, NY: Psychology Press.

Brisk, M. E. (2006). Bilingual Education: From Compensatory to Quality Schooling. Mahwah, NJ: Lawrence Erlbaum Associates.

Bruner, J. \& Olver, R. (1966). Development of Equivalence Transformations in Children. In R. Anderson \& D. Ausubel (Eds.), Readings in the Psychology of Cognition (pp. 415-434). New York, NY: Holt, Rinehart \& Winston.

Bruner, J. (1999). The Process of Education. Massachusetts: Harvard University Press.

Campelo, L. F., \& Bertholo Piconez, S. C. (2016). Concept Mapping in High School: An Experience on Teaching Geography to Measure Deep, Surface and Non-Learning Outcomes. In A. J. Cañas, P. Reiska, \& J. Novak (Eds.), Innovating with Concept Mapping (Vol. 1, pp. 351-354). Switzerland: Springer.

Cañas, A. J., Carvalho, M., Arguedas, M., Leake, D., Maguitman, A., Reichherzer, T. (2004). Mapping the Web to Suggest Concepts during Concept Map Donstruction. In A. J. Cañas, J. D. Novak, \& F. M. González (Eds.), Proceedings of the 1st International Conference on Concept Mapping (Vol. 1, pp. 135-142).

Clariana, R. B. \& Kozlov, M. (2016). The Influence of Graphical or Textual Representations on Team Concept Map Form: Further Validation of a Measure of Knowledge Structure. In A. J. Cañas, P. Reiska, \& J. Novak (Eds.), Proceedings of the 7th International Conference on Concept Mapping (Vol. 2, pp. 351-354).

Clyne, M. (2000). Constraints on Code-Switching: How Universal are They? In Li Wei (Ed.), The Bilingualism Reader (Chapter 10, pp. 241-264). New York, NY: Routledge.

Craig, C. (1986). Theoretical Issues of Categorization and Human Cognition. In Colette Craig (Ed.), Noun Classes and Categorization (Vol. 7, Introduction, pp. 1-10). Philadelphia, PA: John Benjamins.

Crandall, B., Klein, G., \& Hoffman, R. (2006). Working Minds: A Practitioner's Guide to Cognitive Task Analysis. Cambridge, MA: MIT Press.

Cury, D., Andrade, W., \& Santos P. (2014). CMPAAS-A Platform of Services for Construction and Handling of Concept Maps. In P. R. M. Correia, M. E. I. Malachias, A. J. Cañas, \& J. D. Novak (Eds.), Proceedings of the 6th International Conference on Concept Mapping (Vol. 1, pp. 108-115).

Decreto 47/2017, de 25 de julio, por el que se regula el plan integral de enseñanza de lenguas extranjeras de la comunidad autónoma de Castilla-La Mancha para etapas educativas no universitarias. [2017/9118]

De Groot, A. M. B. (2011). Language and Cognition in Bilinguals and Multilinguals. New York, NY: Psychology Press.

Gagné, R. M., Briggs, L. J., Wager, W. W. (1992). Principles of Instructional Design. Orlando, FL: Harcourt Brace Jovanovich.

Gagne, E. D., Yekovich, C. W., \& Yekovich, F. R. (1993). The Cognitive Psychology of School Learning. London: Harper Collins.

Glasersfeld, E. (1995). Radical Constructivism: A Way of Knowing and Learning. London: Routledge.

Gómez Ramos, J. L., Lirio Castro, J., Gómez Barreto, I., Garrote Rojas, D. (2018). Content and Language Integrated Learning via Concept Mapping: Traditional Assessment Difficulties for Verifying Significant Learning in Bilinguals. In Proceedings of INTED 2018. ISBN: 978-84-697-9480-7

Gómez Ramos, J. L., Arias Fernández, E., Lirio Castro, J. (2016). Lexical categories: Concept Mapping Instruction on the Effect of Noun Identification in Foreign Language Texts. In A. J. Cañas, P. Reiska, \& J. D. Novak (Eds.). Proceedings of the Seventh International Conference on Concept Mapping (Vol. 2, pp. 145-154).

Harris, R. L. (1996). Information Graphics: Visual Tools for Analizing, Managing and Communicating. Atlanta, GA: Management Graphics.

Haskell, R. E. (2011). Transfer of Learning: Cognition, Instruction, and Reasoning. San Diego, CA: Academic Press.

Hernández Sheets, R. \& Torres, B. (2010). Bilingual Curriculum. In C. Kridel (Ed.), Encyclopedia of Curriculum Studies (pp. 80-82). Thousand Oaks, CA: SAGE.

Jackson, R. R. (2011). How to Plan Rigorous Instruction. Alexandria, VA: ASCD. 
Jespersen, O. (1956). Essentials of English Grammar. London: Routledge.

Manzanares Moya, M. A., \& Galván-Bovaira, M. J. (2012). In-service Education of Pre-school and Primary School Teachers in Teacher Centres. An Evaluation Model. In José Luis Gaviria Soto (Ed.) Revista de Educación, 359. Septiembre-diciembre 2012 (pp.431-455). DOI: 10.4438/1988-592X-RE-2011-359-101

Mercer, N. (2000). Words and Minds: How We use Language to Think Together. London: Routledge.

Mintzes, J. J., Wandersee, J. H., \& Novak, J. D. (2005). Assessing Science Understanding: A Human Constructivist View. Burlington: Elsevier.

Moreira, M. M. (2012). Freedom to Teach and Learn Literature: The Use of Concept Maps. Bloomington, IN: Palibrio.

Novak, J. D. \& Gowin, D. B. (1984). Learning How to Learn. New York: Cambridge University Press.

Novak, J. D., \& Musonda, D. (1991). A Twelve-year Longitudinal Study of Science Concept Learning. American Educational Research Journal Spring. Vol. 28, No. 1, pp. 117-153.

Novak, J. D. (2010). Learning Creating and using knowledge: Concept Maps as Facilitative Tools in Schools and Corporations. New York: Routledge.

Phye, G. (1997). Learning and Remembering: The Basis for Personal Knowledge Construction. In Gary D. Phye (Ed.), Handbook of Academic Learning: Construction of Knowledge (Chapter 2, pp. 107-115). San Diego, CA: Academic Press.

Piaget, J. (1959). The Growth of Logical Thinking: From Childhood to Adolescence. United States: Basic Books.

Vygotsky, L. S. (1986). Thought and Language. New York, NY: MIT Press. 